\title{
Walking the talk: implementing the international voluntary guidelines for securing sustainable small-scale fisheries
}

Svein Jentoft

Correspondence:

Svein.Jentoft@uit.no

Norwegian College of Fishery

Science, University of Troms $\varnothing$,

Tromsø, Norway

\begin{abstract}
On June 9, 2014 the Committee of Fisheries (COFI) of FAO adopted the Voluntary Guidelines for Securing Sustainable Small-scale Fisheries in the Context of Food Security and Poverty Eradication (SSF-Guidelines). For millions of small-scale fisheries people around the world, this was no doubt a historic event and a potential turning point. The challenge now is to make sure that they will be implemented. As the SSF-Guidelines address issues that are politically contentious, there are reasons to expect that they will be met both with enthusiastic acclamation and criticism, as already happened in the negotiations of the text. This paper discusses the opportunities and obstacles for their implementation.
\end{abstract}

Keywords: FAO; Small-scale fisheries guidelines; Human rights approach; Implementation; Interactive governance

\section{Introduction}

The United Nation's Food and Agriculture Organization (FAO) estimates that 50 of the world's 51 million fishers are small-scale and that most of them live in developing countries $^{\mathrm{a}}$. These small-scale fishers produce nearly half of the fish that is consumed globally and most of the fish consumed in the developing world. In addition, "hundreds of millions of rural people in developing countries depend on fisheries for their livelihood". Despite these big numbers, most small-scale fishers and the communities in which they exist are far from the radar of national, regional and global decisionmaking. There is also uncertainty about the actual figures due to the lack of a global statistical information system. Nevertheless, these estimates certainly make small-scale fisheries sector "too big to ignore"

For this reason, FAO has been spearheading the initiative to develop international guidelines for small-scale fisheries. After years of planning, extensive consultation with civil society organizations (CSOs) and stakeholders, including the research community, and intense negotiation among member states, on June 9, 2014, the Committee of Fisheries (COFI) of FAO adopted the Voluntary Guidelines for Securing Sustainable Small-scale Fisheries in the Context of Food Security and Poverty Eradication (SSFGuidelines). For the millions small-scale fishing people around the world, many of whom are poor and marginalized, this was no doubt an historic event and a potential

(C) 2014 Jentoft; licensee Springer. This is an Open Access article distributed under the terms of the Creative Commons Attribution License (http://creativecommons.org/licenses/by/4.0), which permits unrestricted use, distribution, and reproduction in any medium, provided the original work is properly credited. 
turning point ${ }^{\mathrm{c}}$. Never before has this sector received such global recognition. Expectations are that the Guidelines will make a big difference for small-scale fishing people around the world ${ }^{\mathrm{d}}$. Although the process of adopting the Guidelines has been cumbersome at times, also in the final stage of negotiations, the real challenge now is to make sure that they will be implemented. Even if FAO member states have agreed to the Guidelines, there is no guarantee that they will follow up in practice. As Raustiala and Victor (1989:660) conclude in a different context: "Often, a country adopts an international accord without a clear plan for putting the commitments into practice". As far as the SSF-Guidelines are concerned, the ultimate test is whether states will really 'walk the talk'. However, even if member states hesitate, one should give them the benefit of doubt until evidenced that their support is not sincere.

As the SSF-Guidelines are voluntary and address issues that are politically contentious, they are likely to be met with reluctance or resistance in some quarters. Despite some imprecision in terminology and definition, they are what member states reached consensus on. Indeed, what more than hundred member states supported was quite significant and remarkable.

A full discussion of the substance of the SSF-Guidelines is beyond the scope of this paper $^{\mathrm{e}}$. I will limit myself to pointing out some of the implementation challenges that lie ahead. The paper begins by explaining what the SSF-Guidelines are, what they aim to do, and why small-scale fisheries are difficult to define in the context of the SSFGuidelines. Then follows a discussion on two key implementation issues; the voluntary nature of the SSF-Guidelines and their strong emphasis on human rights. Thereafter, based on the academic literature on the implementation of policies and codes, the prospects of implementing the Guidelines are addressed.

\section{What are small-scale fisheries?}

Quoting from the document preface, the SSF-Guidelines intend "to support the visibility, recognition and enhancement of the already important role of small-scale fisheries and to contribute to global and national efforts towards the eradication of hunger and poverty". The hope is that they will lead to policy change "for the benefit of current and future generations, with an emphasis on small-scale fishers and fish workers and related activities". The SSF-Guidelines will also:

"be in support of national, regional and international initiatives for poverty alleviation and equitable social and economic development, for improving governance of fisheries and promoting sustainable resource utilization. Their objective is to provide advice and recommendations on implementation, establish principles and criteria, and information to assist States and stakeholders to achieve secure and sustainable small-scale fisheries and related livelihoods"g.

As the title points out, the SSF-Guidelines are voluntary, and this is also stressed repeatedly throughout the text. States may therefore choose to ignore them. Although civil society organizations (CSOs) called for the SSF-Guidelines to be binding, they cannot, and perhaps should not, be imposed on States. States cannot be held legally accountable if they decide to disregard or deviate from them. Nevertheless, the Guidelines have been adopted in an open, participatory, consensus and transparent 
process, and can therefore at least be held morally applicable. States can be asked to describe what they have done to implement them and to explain why they decide not to.

The SSF-Guidelines are not just a set of recommendations; they include normative 'meta-governance' principles, intended to 'governing the governance' of small-scale fisheries (Kooiman 2003). The ultimate test will be the effect that the SSF-Guidelines have at the level of local fisheries communities. It must then be taken into account that small-scale fisheries are characterized by enormous diversity (Ratner and Allison 2012; Jentoft and Eide 2011; Chuenpagdee 2011; Berkes et al. 2001). They differ ecologically, organizationally, economically and technologically from one region to the next. They also exhibit attributes that are often unique to a particular fishery or locality.

Moreover, small-scale fisheries are rarely a distinct sector. Rather they are closely connected to, indeed embedded within, a larger social and ecological system - as a "system within systems" - intimately connected with economic, social and cultural life in local communities. Small-scale fisheries are typically family enterprises, often involving women and children whose roles and interests are not always recognized.

Small-scale fisheries must also be understood in relation to large-scale fisheries, as the two are often in conflict (García-Flórez et al. 2014; Bavinck 2005). Keeping the two fisheries apart is a major challenge, since large-scale fishers do not often respect the areas set aside for small-scale fisheries. All these traits call for a governance approach that is holistic and systemic. What is happening within the small-scale fisheries is often due to what is going on outside them.

What is interesting and important about small-scale fisheries, therefore, is not their scale per se, but all that they are associated with. The SSF-Guidelines apply a broad perspective, which attempts to capture inherent and related features. A prevalent stereotype of small-scale fisheries is that it is simple and traditional, and thus lags behind in the modernization process. However, small-scale fisheries technology is often well adapted to the particular ecological and social circumstances within which they must operate. Small-scale fisheries can also be sophisticated in the way they are organized and how they serve markets. They are not necessarily stuck in the past but a dynamic sector undergoing constant change: what they were is not what they are, and certainly not what they might become.

The SSF-Guidelines emphasize the important contribution of small-scale fisheries to food security and poverty alleviation. This implies that small-scale fisheries deserve attention not just for their problems, such as poverty, but also for the opportunities they provide in addressing important societal concerns that exist beyond the sector, such as providing safe and nutritious food (HLPE 2014) and employment. But small-scale fisheries do more than just provide society at large with a 'service'. They are important in themselves. Millions of people depend on them for their livelihood. Small-scale fisheries represent cultural heritage, they offer a way of life, a particular lifestyle that provides both identity and meaning to the lives of those who inhabit them. As Onyango (2011) argues, they are not always 'an occupation of last resort'.

The lack of a precise definition of what small-scale fisheries are in the SSFGuidelines is justified by their extreme diversity globally. Their multi-faceted nature also make definitions complex, rich and 'clumpish' (García-Flórez et al. 2014). The only way to define them is to employ what the anthropologist Clifford Geertz (1973) termed 'thick description'. Thus, for a FAO Working Group on Small-scale Fisheries, the 
definition that eventually emerged filled a whole page (FAO 2005: 4). The Group listed features including technology (boat and gear), multi-species fishing, processing and marketing, communities, gender, labor intensity, organizational characteristics, livelihood, food security, and poverty.

Since those who make the effort to define them use their own particular situation as a point of departure, definitions tend to differ from region to region, and it is often hard to reach a consensus on language. For this reason, small-scale fisheries also go by different names in different countries, with terms such as inshore, coastal, artisanal, municipal, small-boat, community-based, and so forth being used. The SSF-Guidelines use the term small-scale fisheries, but do not offer a definition. Instead, they leave it to countries to define them in a way that fits their particular situation. As shown by Chuenpagdee et al. (2006), most countries do in fact define small-scale fisheries using common features like boat size, gear type, engine power, etc., for the purpose of regulations. Still, the Guidelines have a lot to say about most of the characteristics of small-scale fisheries mentioned above.

\section{How voluntary?}

From the beginning, CSOs throughout the world have been deeply involved in the preparation of the SSF-Guidelines through workshops and consultations. They also played a constructive role during the two Technical Consultations in Rome in May 2013 and in February 2014. Their hands-on experience with the situation in small-scale fisheries was often decisive for the language that ended up in many of the guideline articles. In a lengthy comment on the zero draft presented by the FAO secretariat, they requested that the Guidelines should be binding ${ }^{\mathrm{h}}$. This would obviously have changed the legal status of the SSF-Guidelines, which most likely would have made it more difficult for member states to endorse them. A preceding document, the Code of Conduct for Responsible Fisheries, is not binding either. The same is with other FAO guidelines that are frequently referred to in the document, such as the Voluntary Guidelines to Support the Progressive Realization of the Right to Adequate Food in the Context of National Food Security and the Voluntary Guidelines on Responsible Governance of Tenure of Land, Fisheries and Forests in the Context of National Food Security. The repeated insistence that the SSF-Guidelines are voluntary (mentioned 18 times in the document), makes it easier for States to acquiesce, since they also have the choice of non-implementation. If the SSF-Guidelines had the status of a UN convention, one might have expected a more demanding and time-consuming negotiation process (but perhaps an easier implementation).

Consequently, there was willingness to compromise, also among those who would have preferred more commitment and a stronger text. Yet, negotiations proved more time-consuming than anticipated. In particular sections, the voluntary issue is present by implication more than by intention. For instance, the fact that the SSF-Guidelines do not prescribe a standard definition of small-scale fisheries and how it should be applied in a national context, creates flexibility as to their interpretation and, hence, implementation. Countries may therefore decide themselves who the SSF-Guidelines are relevant for - or, indeed, if they are relevant at all. It will thus be interesting to see how States now choose to define small-scale fisheries in the context of the Guidelines. There 
will always be room for ambiguity and interpretation as definitions contain words that may themselves be in need of such. For instance, what does it mean to be poor? The poverty concept has over time undergone considerable change, from a narrow focus on income to include aspects such as health, education and empowerment (Béné 2003). Small-scale fishers are not necessarily among the poorest of the poor in income and subsistence terms (Bavinck 2014), but they are often poor in terms of these other variables (Kurien and Willmann 2009). Poverty is also relative. Small-scale fishers may be deprived in comparison with other groups in their country but not necessarily in an absolute sense - as is often the situation in the north (Jentoft and Midré 2011). They may be poor because they are vulnerable, and vice versa, or because they are marginalized (Islam 2011). What comes first is not easy to say. If these terms had been more elaborate in the text, countries in the developed north would perhaps have found the Guidelines more relevant for their own small-scale fisheries.

\section{The human-rights approach}

As stressed throughout the document, the SSF-Guidelines should be implemented in accordance with national legal systems and their institutions. This would have gone without saying if it had not been for the fact that the SSF-Guidelines also underscore the need for legal reform. If every country insists that the Guidelines should be in conformity with existing domestic policies and legislation, there is a risk that their implementation ends up confirming the status quo, or that they would only lead to insignificant reform. The national legal lens may suggest that member states are cautious to commit.

In a communication with this author during the Technical Consultation in May 2013, the representative of the UN High Commission on Human Rights argued that it is important also for small-scale fisheries to have access to justice and to effective remedies not only guaranteed by national but also by international law. By explicitly linking the SSFGuidelines to 'hard' international law (such as the International Covenant on Civil and Political Rights, the International Covenant on Economic, Social and Cultural Rights, the Convention on the Elimination of All Forms of Discrimination against Women, the Convention on the Rights of the Child) the SSF-Guidelines are less voluntary than they appear. It is for this reason probably that during the Technical Consultations some delegates felt uneasy about the frequent reference (29 times) to human rights in the text.

The Human Rights Approach (HRA) to fisheries governance has received both support and criticism. Allison et al. (2012:14) see the need to move beyond the narrow perception of property rights as a fisheries governance tool, to a broader human rightsapproach. This, they view as a means to "enhance the chances of achieving both human development and resource sustainability outcomes in small-scale fisheries..." These authors criticize the idea of 'rights-based fishing' for advocating property-rights and privatization, which tend to lead to exclusion of poor and vulnerable small-scale fisher groupsi. Potentially, fisheries/property rights and human rights are in conflict, as was, for instance, demonstrated with the UN Human Rights Committee's ruling on the Icelandic quota system in 2007 (Einarsson 2004) .

In contrast to Allison et al. (2012), Ruddle and Davis (2013) perceive the HRA to small-scale fisheries as a neo-liberal idea. As they see it, there is a risk that 'human rights rhetoric' may discredit "customary practices and separate the individual from 
her/his social contexts and relationships." (Ibid: 89). Given the universality of human rights principles, the two authors fear that such an approach will 'homogenize' "diverse human conditions and cultures" (Ibid: 91). If valid, this criticism, would also affect the SSF-Guidelines. Ruddle and Davis are referring to Donnelly (2013), but seem to disregard this statement:

"Human rights today remain the only proven effective means to assure human dignity in societies dominated by markets and states... Virtually everyone on this planet today lives in a world of modern markets and modern states which need to be tamed by human rights if those powerful institutions are to be made compatible with the life of dignity for the average person" (Ibid: 97) .

In his keynote address at the 2013 People and the Sea conference in Amsterdam, FAO's Rolf Willmann, who is also one of Allison's co-authors and the main architect of the SSF-Guidelines, commented on the Ruddle and Davis article (Willmann et al. 2013). First, he pointed out that human rights constitute both domestic and international law. The implication is that human rights violations in small-scale fisheries can be prosecuted at both levels. All $192 \mathrm{UN}$ member states have also signed on to the Universal Declaration of Human Rights. Secondly, although Ruddle and Davis refer to Amartya Sen (1999), Willmann argues that they miss his point that human rights legislation secures basic entitlements and freedoms without which development cannot take place. Thirdly, Willmann takes issue with the notion that tenure arrangements advocated through the HRA are necessarily individualistic, and that this approach excludes opportunities for community and collective tenure. Many of the SSF-Guidelines articles do indeed refer to communities (mentioned 77 times), culture (19 times), customary rights and practices (10 times), and indigenous peoples (10 times), and it is important to note that these were not viewed as controversial concepts during the Technical Consultation. Indeed, delegates had no problem with the "s" in peoples - a letter that determines whether the text refers to individual or collective rights. Concepts like governance, co-management, redistribution, informal sector, and human rights standards (as opposed to law) met objections but still survived. One State, however, uttered strong objections to the term 'situations of occupation' proposed for Article 6.18, which until the final hour of the COFI meeting threatened to overturn the adoption of the SSF-Guidelines.

The sometimes heated negotiations on the text do suggest that member states take the SSF-Guidelines seriously. It also indicates that the implementation process is likely to be cumbersome, as the concrete meaning of general concepts and norms, and what they imply, will need to be defined for particular situations. The negotiation on the SSF-Guidelines therefore does not stop with COFI's endorsement.

\section{Implementation challenges}

Implementation is the process by which "intent is translated into action" (Rein and Rabinovitz 1987:308). Now that member States have endorsed the SSF-Guidelines, the former is settled and the latter is about to begin. Most likely, however, the implementation of the SSF-Guidelines will not be a graceful, straightforward transition. Rather, one should expect a cyclical, interactive, and iterative process, where original objectives are subject to repeated questioning, debate, evaluation and reformulation. Lessons learned 
in the course of implementation may lead to reconsideration of the original intent and to subsequent reformulation of principles and goals. The stated principles, and the values and norms underpinning them, are therefore not stable, at least not in the long run. Their interpretation may change over time.

\section{Technical or political?}

SSF-Guidelines are meant to spur new legislation. Initiatives in this regard would be a clear sign that governments are both willing and able to move from intent to action. As far as legislative reform is zero-sum (as when aimed at redistribution), probability is high that the Guidelines will meet pressure in order to maintain the status quo. Legislative reform and implementation are separate processes, but both are up-hill battles. The burden of proof rests with those who want change, not with those who defend the current order. As Machiavelli already observed, "it must be considered that there is nothing more difficult to carry out, nor more doubtful of success (...), than to initiate a new order of things. For the reformer has enemies in all those who profit by the old order, and only lukewarm defenders in all those who would profit by the new order..." ([1532] Machiavelli 1950: 21).

The SSF-Guidelines promote norms and principles about issues that are social and ethical. They are meant to intervene in situations where different interests are in conflict and where small-scale fisheries are the weaker party. They will inevitably interfere with power. The Guidelines and their implementation are therefore as political as technical. As stated in the Preface:

"Small-scale fishing communities also commonly suffer from unequal power relations. In many places, conflicts with large-scale fishing operations are an issue, and there is increasingly high interdependence or competition between small-scale fisheries and other sectors. These other sectors can often have stronger political or economic influence, and they include: tourism, aquaculture, agriculture, energy, mining, industry and infrastructure developments."

When, during the Technical Consultation, delegates were arguing about language, they were not only considering conceptual clarity and precision but also their own national interests. They were as much concerned about what the SSF-Guidelines might imply for national interests as what they would do for small-scale fisheries globally. In the meeting, delegates therefore sometimes had to consult their capitals, i.e. own governments, about what they could go along with. This in itself suggests a political rather than a technical nature of the SSF-Guidelines.

Unavoidably, as the quotation above indicates, translating intent into action may have consequences not just for small-scale fisheries but also for other stakeholders inside or outside the fishing industry. One may assume this was their concern when some country delegates had problems with 'redistributive reforms', but the term survived ${ }^{1}$. The most controversial issues tend to be phrased in ways that allow interpretation flexibility. Some delegates argued for less gender specific language, to the dismay of civil society representatives who forcefully - and successfully - spoke up to defend the proposed wording. The gender equity perspective has a separate chapter in the Guidelines and otherwise crosscuts the entire document: 'Gender' is mentioned 22 times, 'women' 50 times. 
Neutralizing or removing controversial concepts watered down the text and made it more 'voluntary'as it were, whereas explicit and precise definitions have the opposite effect. But less ambiguity would have made it more difficult to reach agreement Regardless of their legal status, voluntary guidelines are better than no guidelines at all. Therefore many delegates were satisfied with a lower level of exactitude. However, this may eventually make the implementation process more challenging.

\section{Implementation as interaction}

The implementation of the SSF-Guidelines needs an overseer, and FAO is well positioned to play such a role. However, FAO might benefit from building a "system for implementation review" (Victor et al. 1998) involving among others, academics experienced in such research. CSOs also have an important function in the implementation process as perhaps the most important watchdog. States, which are the main recipient of the SSF-Guidelines, control essential legal, financial, technical resources, and must therefore contribute. They must also be part of the feedback loop, where actual accomplishments are reported on, as is the case with the Code of Conduct for Responsible Fisheries.

One should not necessarily expect a top-down implementation process. This is especially because of the current move "from government to governance" in many countries (Bevir 2011), including fisheries (Kooiman et al. 2005, Bavinck et al. 2013). This move results in a more open, inclusive and interactive form of governing where stakeholders have a more proactive role to play (Hill and Hupe 2009; Bellamy and Palumbo 2010) in accordance with 'good governance' principles such as democracy, equity, transparency and accountability. Interactive governance puts pressure on governments to become more accommodating to stakeholder interests and concerns. It transforms the role of the State from supreme governor to mediator, negotiator and facilitator.

The SSF-Guidelines took a lot of flexibility by involved parties to reach consensus, and their implementation too will still depend on it. In the course of implementation, they will have to be operationalized and contextualized. As new participants are drawn into the process, people who have not so far been involved will have to be convinced about their merits. In this process enthusiasm might get lost. Therefore, as Susskind (2006: 282) argues, "even though the parties to a mutual gains negotiation are almost always satisfied with the outcome (or they would not have agreed to accept it), they still need to worry about the mechanisms of implementation". Parties must therefore invest time in crafting the best ways of making their agreement "nearly self-enforcing". This may require "adding incentives or disincentives to the terms of the agreement." (Susskind 2006: 282) Which incentives would be required as far as the implementation of the SSF-Guidelines is concerned are not clear at this point but must be defined and agreed upon as part of the implementation process.

Implementation depends as much on the messenger as the message. The SSF-Guidelines may be met with skepticism just because it is the central government that is sponsoring them, especially if the track record of supporting small-scale fisheries is poor. Why this sudden change of government attitude? Is there perhaps a hidden agenda somewhere? As Tsang et al. (2009: 101) point out:

"Although government may be able to implement its own agenda without trust or exert absolute control over a population through the use of coercive resources, it is 
nowadays impossible to implement the programs of a modern state effectively without trust. A government has a great deal to gain by facilitating trust."

The implementation of the SSF-Guidelines will therefore hinge on the legitimacy and trust that the state government enjoys among stakeholders. For this reason also, the implementation process must be interactive, as participation tends to increase stakeholder cooperation and compliance (Susskind 2006; Jagers et al. 2012).

Signing up to conventions, declarations, or, in this case the SSF-Guidelines, has symbolic value: it shows goodwill. But it may also be an effort of window-dressing in order to make the authorities look good to the international community and domestic constituents. Sometimes governments implement what they have committed themselves to because of external demands to follow up. For instance, as far as international environmental codes are concerned, Raustiala and Victor (1989:671) conclude that "minimal implementation of international environmental commitment in these states mainly reflects low public pressure for environmental protection". There is little reason to expect that the implementation of the SSF-Guidelines would be any different.

It is therefore probably crucial that CSOs, like those who have been involved in the development of the SSF-Guidelines, along with research community and public at large, act to prevent this from happening. CSOs are often "the first to spot deviations from the terms of consensus-based rights and rules" (Young 2006: 851). FAO too may play this role. FAO may also encourage CSOs and the academic community to do their part, as it outlines in a follow up document that was presented to COFI $^{\mathrm{m}}$. All this would turn implementation into a trickle-up as well as a trickle-down process, as illustrated in Figure 1. To act, governments would first need to be reminded from below what they at COFI have agreed to.

\section{Implementation obstacles}

According to Rein and Rabinovitz (1987), implementation is generally subject to three hurdles - or 'imperatives': a legislative hurdle, a bureaucratic one and one regarding consensus-building. The SSF-Guidelines would have to pass all three. First, what is legally required in order to bring about change for small-scale fisheries may vary from

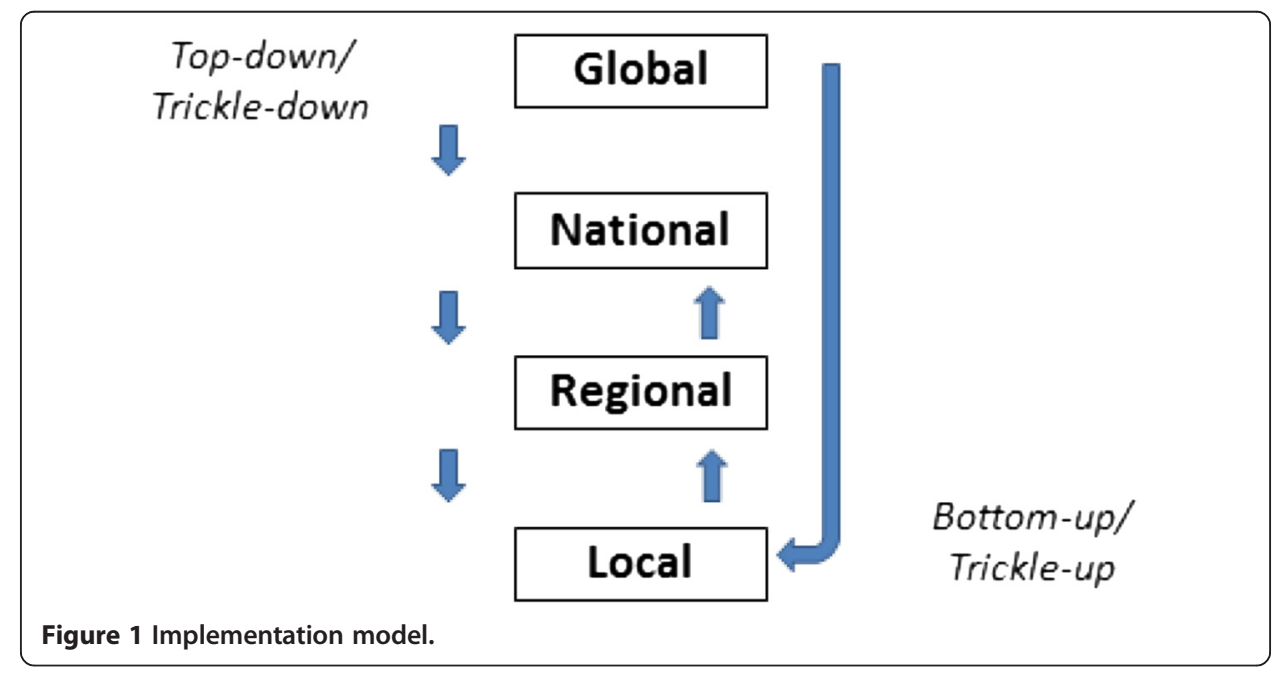


country to country. Therefore, it makes sense to add the phrase "as appropriate", which happens frequently (18 times) in the SSF-Guidelines text. The legal status of small-scale fisheries would need to be clarified in particular cases, and in some countries, as mentioned, new legislation may be required to accommodate the change that the SSFGuidelines aim for. Legal processes and other governance reforms for improving the rights of small-scale fishing people are taking place in some countries, such as South Africa (Sowman et al. 2014) and Cambodia (Ratner et al. 2013). These provide insights into the conditions for successful implementation of the SSF-Guidelines in other settings as well.

Secondly, even if endorsed at the legislative level, there is no guarantee that implementation initiatives will pass the bureaucratic hurdle. Bureaucratic rules and demands are not always conducive to effective implementation. Bureaucrats have ideas about what is feasible from an administrative point of view, for instance because of available data, which in the case of small-scale fisheries are often scant. Who are small-scale fishers, how many and where are they? The implementing agency would need to have this information as implementation would otherwise easily misfire. Policies may not reach the poorest and most marginalized of small-scale fishers, i.e. those who the SSF-Guidelines especially have in mind.

Should the implementation process pass the second hurdle, it would next have to face the industry and all other stakeholders who may or may not agree with the notion that small-scale fisheries deserve special attention. Without consensus about the need to act upon the SSF-Guidelines, implementation may come to a halt. There is also the risk of regulatory capture by special interest groups. Powerful stakeholders may attempt to bend the SSF-Guidelines to their benefit. The implementation must therefore be sensitive to power differences, also those that exist within small-scale fisheries, for instance between boat owners and crew (Jentoft 2007; Cooke and Kothary 2002). Raustiala and Victor (1989:669), however, find that "while regulatory capture is a risk, the capturing influence of target groups has been offset through informed participation by countervailing groups". Again, this calls for broad and transparent participation in the SSF-Guidelines implementation process.

Over time, partly due to power struggle, goal displacement is to be expected. This may cause disappointment among those who initially had high expectations of the Guidelines and for whom they were primarily intended. This is particularly the danger when implementation is not controlled by a single authority but is open to negotiation among multiple parties, as within interactive governance. Implementing agencies and stakeholders must be prepared for this eventuality, as goal displacement may easily go unnoticed (Jentoft et al. 2011).

Thus, implementation is a process with uncertain outcomes, especially in small-scale fisheries where issues tend to be politicized (see for example Scholtens et al. 2013). Since the SSF-Guidelines are voluntary, outcomes are particularly unpredictable. Raustiala and Victor (1989: 660-1) observe:

"When national implementation is complex, more political and economic interests are likely to be affected, leading to political mobilization and shifting coalitions. Typically these coalitions become more complicated, with less predictable outcomes..."

Despite this risk, and for the reasons mentioned above, the broad scope of the SSF-Guidelines requires an implementation process that builds coalitions. Whether 
countries with a tradition of stakeholder participation are more inclined than others to effectively implement the SSF-Guidelines in an inclusive manner is an empirical question. Research on the implementation of environmental codes suggests that "participation during the negotiations of international commitments and the making of national implementing policy is high, but it has often proved difficult to expand participation at the implementation phase" (Victor et al. 1998:23). Some countries may already have robust institutions in place that help facilitate implementation, while others may have to create them first. Institutional development is therefore an integral part of the implementation process in many situations. Parallel to the negotiations on the SSF-Guidelines, FAO initiated a process of investigating the organizational conditions of small-scale fisheries to prepare for implementation (Kalikoski and Franz 2014).

The relative economic importance of small-scale fisheries and the level of development and industrialization may all affect willingness to implement the SSF-Guidelines. In the Preface section it is emphasized that not only are the Guidelines "global in scope", but that also they have a "focus on the needs of developing countries". State governments in the developed North may here find an excuse for distancing themselves from the Guidelines. Crises may also influence implementation (cf. Krämer 2006). Policy change in fisheries often occurs when some emergency calls for action. One may, therefore, not expect much action on the SSF-Guidelines if the state of affairs in the fishing industry is characterized by tranquility, development, and growth. If small-scale fisheries are in a bad condition but still "too big to ignore", as is the situation in many developing countries, the SSF-Guidelines are more prone to find fertile ground. Developed countries, on the other hand, can perhaps afford to ignore small-scale fisheries (although they are likely marginalized and can benefit from the implementation of the SSF-Guidelines) whereas less well-off countries may find them more relevant.

\section{Measuring outcomes}

The overseer (FAO and partners) would need a suitable monitoring and evaluation plan and a measurement instrument. The study conducted by Pitcher et al. (2009) is an example of what can be done. These authors compared country compliance with the Code of Conduct for Responsible Fisheries, and found substantial variation. However, this study measured conformity, not achievement. Countries may already have been living up to the principles of the Code at the time it was initiated, or their policies may have been initiated regardless thereof. What the overseer would want to know is whether the SSF-Guidelines are precipitating to real policy change and whether they are actually making a difference to small-scale fisheries. The latter might be more difficult to establish due to the presence of other causal factors. Ideally, one would need to know what small-scale fisheries would have been without the SSF-Guidelines, and be able to separate other variables having influence. But small-scale fisheries are a dynamic sector, in which internal and external drivers that are hard to control cause constant change. The SSF-Guidelines may therefore at best partially impact on how small-scale fisheries are developing.

\section{Concluding remarks}

With regard the implementation of the SSF-Guidelines, one should expect considerable variation between countries as institutional contexts, policy agendas and the preferences 
of key agents and participants differ from one another. Countries do not have the same capacity to act, causing therefore what is often called an 'implementation gap', defined by Hinds (2003: 350) "as the gap between the approval and the implementation of intergovernmental/international conventions, agreements, resolutions and recommendations". State governments may sometimes lack what Cappelli (2008) termed "stateness" i.e. the capacity, power and control of states to implement public policies. Indeed, the SSFGuidelines are targeted at governments that in many instances would fit Gunnar Myrdal's

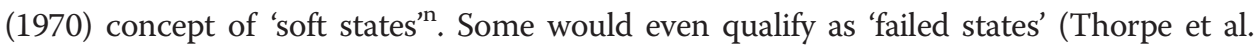
2009). If the capacity to implement legislation is generally low, there is little reason to assume that it will be much different in the case of the SSF-Guidelines. In fact, both the willingness and capacity to implement policies with regard to small-scale fisheries are often lacking (cf. Carbonetti et al. 2014, Ratner et al. 2013). CSOs may be called for to fill the gap (Béné et al. 2004), but are usually short on resources. Therefore, capacities need to be developed at all levels to help implement the SSF-Guidelines.

Implementation is often time-consuming and incremental but without a clear stopping rule. The SSF-Guidelines may therefore take years to take full effect. But when can one say that their implementation is actually complete? The Guidelines may be implemented to some extent, but not necessarily to the full. Implementation is likely to be an ongoing, adaptive and iterative process, as small-scale fisheries are dynamic. Although the governance principles that are stated in the SSF-Guidelines may remain, the policies and actions that follow from them must change according to how these fisheries are developing and what lessons are learned in the process implementing them.

The implementation of the Guidelines would for these reasons clearly qualify as a 'wicked problem', as Rittel and Webber (1973) coined it (see also Jentoft and Chuenpagdee 2009). The parties involved, also those in charge of monitoring and evaluation, are in for a long haul. Consequently, monitoring should be longitudinal, following the implementation process as it unfold at all levels of governance. People with experience in implementation research have relevant knowledge on how to set baseline and monitor progress. The literature points out, however, that studies of implementation processes are in themselves costly and time-consuming (Goggin et al. 1990: 205). The States that the SSF-Guidelines are addressing have a responsibility to provide such funding. Indeed, their willingness to do so would be a sign of how serious and supportive they are.

The lessons learned from the implementation of the Code of Conduct and other FAO guidelines are particularly relevant. The SSF-Guidelines are interlinked with the Food security guidelines and the Tenure guidelines. Evaluating the implementation SSF-Guidelines will also partially be evaluations of these other instruments. To separate the impact that the SSF-Guidelines have would, consequently, be difficult. But then, at the end of the day, what really matters are whatever positive changes take place in small-scale fisheries globally, and not which instrument such success can be attributed to.

\section{Endnotes}

${ }^{a}$ http://www.fao.org/fishery/ssf/people/en.

bhttp://toobigtoignore.net/.

${ }^{c}$ https://sites.google.com/site/smallscalefisheries/events.

${ }^{d}$ http://igssf.icsf.net/en/page/1053-FAO\%20SSF\%20Guidelines\%20Adopted.html. 
${ }^{\mathrm{e}}$ The reader will find the full text at http://www.fao.org/fishery/ssf/guidelines/en.

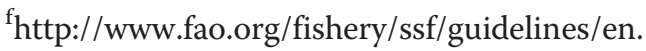

${ }^{g}$ http://www.fao.org/fishery/ssf/guidelines/en.

${ }^{\mathrm{h}} \mathrm{CSO}$ comments on the zero draft of the FAO International Guidelines for Securing Sustainable Small-scale Fisheries. Dated 15 February 2013.

iThis concept was suggested by a delegate during the Technical Consultation, but was rejected.

'The UN Human Rights Committee ruled that the Icelandic state had infringed the human rights of two fishers violating article 26 of the International Covenant on Civil and Political Rights by introducing an ITQ system that effectively denied them access to the fisheries. http://www.liu.is/files/\%7Bf1e88c18-c051-46f1-8468-7f987b05736f\%7D_ccpr_3016-2004_ fagrimuli.pdf. Iceland was also the country who most strongly disassociated itself from the SSF-Guidelines during COFI, stressing that the guidelines are only relevant for developing countries.

${ }^{\mathrm{k}}$ In a similar vein, Gutmann (2001:xxi) argues that "what human rights protection seeks is not the destruction of cultures, as critics too often accuse, but the integration of human rights protections as critics too often deny is possible".

${ }^{\text {l} P a r a g r a p h} 5.8$ reads: "States should adopt measures to facilitate equitable access to fishery resources for small-scale fishing communities, including, as appropriate, redistributive reform, taking into account the provisions of the Voluntary Guidelines on Responsible Governance of Tenure of Land, Fisheries and Forests in the Context of National Food Security".

mhttp://www.fao.org/cofi/23150-06f3fe142a720e59e7e957ad95a0f916a.pdf. Here also the TBTI (Too Big To Ignore) research network is mentioned by FAO as one important potential contributor. A new meeting to develop the implementation strategy is scheduled for December 2014.

${ }^{\mathrm{n}}$ To Myrdal, the concept refers to "all the various types of social indiscipline which manifest themselves by deficiencies in legislation and, in particular, law observance and enforcement, a widespread disobedience by public officials and, often, their collusion with powerful persons and groups ... whose conduct they should regulate. Within the concept of the soft states belongs also corruption” (Myrdal 1970: 208).

${ }^{\circ}$ http://toobigtoignore.net/.

${ }^{\mathrm{p}}$ http://www.fao.org/fsnforum/forum/discussions/SSF_Guidelines.

Competing interests

The author declares that he has no competing interests.

Acknowledgements

This paper is written as a contribution from the TBTI (Too Big To Ignore) research network in which this author is a working group leader and steering committee member ${ }^{\circ}$. The section on implementation was first submitted to the e-consultation on the SSF-Guidelines that took place in November and December 2013 ${ }^{\mathrm{P}}$. I am grateful for constructive comments on an earlier draft of this paper by Rolf Willlmann (recently retired from FAO), Nicole Franz of FAO, Ratana Chuenpagdee and Maarten Bavinck of TBTI. Rolf Willmann also invited me to take part in the 2008 global conference in Bangkok on "Securing Sustainable Small-Scale Fisheries", 13-17 October 2008, which initiated the process of developing the SSF-Guidelines, and to brainstorming on the SSF-Guidelines at FAO headquarters in Rome in February 2012. Much appreciated is also the invitation by Johán Williams of the Norwegian Ministry of Fisheries and Coastal Affairs and COFI chair, and Kirsten Bjøru of NORAD to be a member of the Norwegian delegation to the Technical Consultations on the SSF-Guidelines in June 2013 and in February 2014, and at the COFI meeting in June 2014. Clive Tyrell helped with the English editing.

Received: 7 July 2014 Accepted: 21 September 2014

Published online: 05 November 2014

References

Allison, EH, BD Ratner, B Åsgård, R Willmann, R Pomeroy, and J Kurien. 2012. Rights-based fisheries governance: from fishing rights to human rights. Fish and Fisheries 13: 14-29. 
Bavinck, M. 2005. Understanding fisheries conflicts in the South-A legal pluralist perspective. Society and Natural Resources 18(9): 805-820.

Bavinck, M. 2014. Investigating poverty through the lens of riches: immigration and segregation in Indian capture fisheries. Development Policy Review 32(1): 33-52.

Bavinck, M, R Chuenpagdee, S Jentoft, and J Kooiman (eds.). 2013. Governability of Fisheries and Aquaculture. Theory and Applications. Dordrecht: Springer.

Bellamy, R, and A Palumbo (eds.). 2010. From Government to Governance. Aldershot: Ashgate Publishing Company.

Béné, C. 2003. When fishery rhymes with poverty: a first step beyond the old paradigm on poverty in small-scale fisheries. World Development 31(6): 949-975.

Béné, C, E Bennett, and A Neiland. 2004. The Challenge of Managing Small-Scale Fisheries wit Reference to Poverty Alleviation. In Poverty and Small-Scale Fisheries in West-Africa, eds. A Neiland and C Béné. Dordrecht: Kluwer Academic Publisher.

Berkes, F, R Mahon, P McConney, R Pollnac, and R Pomeroy. 2001. Managing Small-Scale Fisheries. Ottawa: International Development Research Centre.

Bevir, M. 2011. The SAGE Handbook of Governance. London: Sage Publications Inc.

Cappello, O. 2008. Pre-modern state building in post-Soviet Russia. Journal of Communist Studies and Transition Politics 24(4): 531-572.

Carbonetti, B, R Pomeroy, and DL Richards. 2014. Overcoming the lack of political will in small scale fisheries. Marine Policy 44: 295-301.

Chuenpagdee, R (ed.). 2011. Contemporary Visions for World Small-Scale Fisheries. Delft: Eburon.

Chuenpagdee, R, L Liguori, MLD Palomares, and D Pauly. 2006. Bottom-up, global estimates of small-scale fisheries catches. Vancouver: University of British Columbia Fisheries Centre Research Report 14(8): $110 \mathrm{p}$.

Cooke, B, and U Kothari. 2002. Participation: The new Tyranny? London: Zed Books.

Donnelly, J. 2013. Universal Human Rights in Theory and Practice. Ithaca University Press: Cornell.

Einarsson, N. 2004. Fisheries governance and social discourse in post-crisis Iceland; Responses to the UN Human Rights Committee's views in case 1306/2004. The Yearbook of Polar Law 3: 479-515.

FAO. 2005. Increasing the Contribution of Small-Scale Fisheries to Poverty Alleviation and Food Security, 481. Rome: FAO Fisheries Technical Paper.

García-Flórez, L, J Morales, MB Gaspar, D Castilla, E Mugerza, P Berthou, L García de la Fuente, M Oliveira, O Moreno, JJ García del Hoyo, L Arregi, C Vignot, R Chapela, A Murillas. 2014. A novel and simple approach to define artisanal fisheries in Europe. Marine Policy 44: 152-159.

Geertz, C. 1973. Thick Description: Toward an Interpretive Theory of Culture. In The Interpretation of Cultures: Selected Essays, 3-30. New-York/N.Y./USA etc: Basic Books.

Goggin, ML, A O'M Bowman, JP Lester, and LJ O'Toole Jr. 1990. Implementation Theory and Practice: Towards a Third Generation. Glenview, III.: Scott, Foreman/Little, Brown Higher Education.

Gutmann, A. 2001. Introduction. In Human Rights as Politics and Idolatry. Princeton: Princeton University Press,

Hill, M, and P Hupe. 2009. Implementing Public Policy. An Introduction to the Study of Operational Governance. London: Sage Publications Ltd.

Hinds, L. 2003. Oceans governance and the implementation gap. Marine Policy 27: 349-356.

HLPE. 2014. Sustainable Fisheries and Aquaculture for Food Security and Nutrition. Rome: A report by the High Level Panel of Experts on Food Security and Nutrition of the Committee on World Food Security.

Islam, MM. 2011. Living on the Margin: The Poverty-Vulnerability Nexus in the Small-Scale Fisheries of Bangladesh. In Poverty Mosaics: Realities and Prospects in Small-Scale Fisheries, eds. S Jentoft and A Eide. Dordrecht: Springer Science.

Jagers, S, D Berlin, and S Jentoft. 2012. Why Comply? Attitudes towards harvesting regulations among Swedish fishers. Marine Policy. 36: 969-976.

Jentoft, S. 2007. In the power of power. The understated aspect of fisheries and coastal management. Human Organization 66(4): 426-437.

Jentoft, S, and R Chuenpagdee. 2009. Fisheries and coastal governance as a wicked problem. Marine Policy 33: 553-560.

Jentoft, S, and A Eide (eds.). 2011. Poverty Mosaics: Realities and Prospects in Small-Scale Fisheries. Dordrecht: Springer Science.

Jentoft, S, and G Midré. 2011. The Meaning of Poverty: The Conceptual Issues in Small-Scale Fisheries. In Poverty Mosaics: Realities and Prospects in Small-Scale Fisheries, eds. S Jentoft and A Eide, 43-70. Dordrecht: Springer Science.

Jentoft, S, R Chuenpagdee, and J Pascual. 2011. What MPAs are for. On goal formation and displacement. Ocean and Coastal Management 54(1): 75-83.

Kalikoski, D, and N Franz. 2014. Strengthening Organizations and Collective Action in Fisheries. A way Forward in Implementing the International Guidelines for Securing Sustainable Small-Scale Fisheries. Rome: FAO Fisheries and aquaculture proceedings. №. 32.

Kooiman, J. 2003. Governing the Governance. London: Sage Publications.

Kooiman, JM Bavinck, S Jentoft, and R Pullin (eds.). 2005. Fish for Life. Interactive Governance for Fisheries. Amsterdam: Amsterdam University Press.

Krämer, L. 2006. The EU: A Regional Model? In Multilevel Governance of Global Environmental Change: Perspectives from Science, Sociology and the law, ed. G Winter. Cambridge: Cambridge University Press.

Kurien, J, and R Willmann. 2009. Special Considerations for Small-Scale Fisheries Management in Developing Countries. In A Fishery Manager's Guidebook, eds. KL Cochrane and SM Garcia. Oxford: Wiley-Blackwell.

Machiavelli, N. 1950. The Prince and Discourses. New York: The Modern Library.

Myrdal, G. 1970. The Challenge of World Poverty. New York: Vintage Books.

Onyango, P. 2011. Occupation of Last Resort? Small-Scale Fishing in Lake Victoria, Tanzania. In Poverty Mosaics: Realities and Prospects in Small-Scale Fisheries, eds. S Jentoft and A Eide, 97-124. Dordrecht: Springer Science.

Pitcher, T, D Kalikoski, G Pramod, and K Short. 2009. Not honouring the code. Nature 457: 658-659.

Ratner, B, and EH Allison. 2012. Wealth, rights, and resilience: an agenda for governance reform in small-scale fisheries. Development Policy Review 30(4): 371-398. 
Ratner, BD, P Cohen, B Barman, K Mam, J Nagoli, and EH Allison. 2013. Governance of aquatic agricultural systems: analyzing representation, power, and accountability. Ecology and Society 18(4): 59. http://dx.doi.org/10.5751/ES06043-180459.

Raustiala, K, and DG Victor. 1989. Conclusions. In The Implementation and Effectiveness of International Environmental Commitments: Theory and Practice, eds. DG Victor, K Raustiala, and B Skolikoff. Cambridge, Mass: The MIT Press.

Rein, M, and FF Rabinovitz. 1987. Implementation: A Theoretical Perspective. In American Politics and Public Policy, ed. WD Burnham and M Wagner Weinberg. Cambridge, Mass: The MIT Press.

Rittel, HWJ, and MM Webber. 1973. Dilemmas in a general theory of planning. Policy Sciences 4: 155-169.

Ruddle, K, and A Davis. 2013. Human rights and neo-liberalism in small-scale fisheries: Conjoined priorities and processes. Marine Policy 39: 87-93.

Scholtens, Joeri, Johny Stephen, and Ajit Menon. (2013). Between the devil and the not-so-deep blue sea. Asymmetrical power in the Indo-Sri Lankan fisheries conflict. Broker Online, http://www.thebrokeronline.eu/Articles/Between-thedevil-and-the-not-so-deep-blue-sea.

Sen, A. 1999. Development as Freedom. Oxford: Oxford University Press.

Sowman, M, J Sunde, S Raemaekers, and O Schultz. 2014. Fishing for equality: policy for poverty alleviation for south Africa's small-scale fisheries. Marine Policy 46: 31-42.

Susskind, L. 2006. Arguing, Bargaining, and Getting Agreement. In The Oxford Handbook of Public Policy, ed. M Moran, M Rein, and RE Goodin, 269-295. Oxford: Oxford University Press.

Thorpe, A, D Whitmarsh, E Ndomahina, A Baio, and M Kemokai. 2009. Fisheries and failed states; the case of sierra leone. Marine Policy 33: 393-400.

Tsang, S, M Burnett, P Hills, and R Welford. 2009. Trust, public participation and environmental governance in Hong Kong. Environmental Policy and Governance. 19: 99-114.

Victor, DG, K Raustiala, and B Skolikoff (eds.). 1998. The Implementation and Effectiveness of International Environmental Commitments: Theory and Practice. Cambridge, Mass.: The MIT Press.

Willmann, R, K Westlund, and T Mclnerney. 2013. A Human Rights-Based Approach in Small-Scale Fisheries - a Quest for Development as Freedom. Paper Presented at the Mare Conference VII: People and the Sea. Amsterdam: University of Amsterdam. June 26-28.

Young, O. 2006. Choosing Governance Systems. In The Oxford Handbook of Public Policy, ed. M Moran, M Rein, and RE Goodin. Oxford: Oxford University Press.

doi:10.1186/s40152-014-0016-3

Cite this article as: Jentoft: Walking the talk: implementing the international voluntary guidelines for securing sustainable small-scale fisheries. Maritime Studies 2014 13:16.

\section{Submit your manuscript to a SpringerOpen ${ }^{\circ}$ journal and benefit from:}

- Convenient online submission

- Rigorous peer review

- Immediate publication on acceptance

- Open access: articles freely available online

- High visibility within the field

- Retaining the copyright to your article

Submit your next manuscript at $\gg$ springeropen.com 